\title{
Reduction of aerosols and splatter generated during ultrasonic scaling by adding food-grade thickeners to coolants: an in-vitro study
}



Received: 23 September 2021 / Accepted: 27 October 2021 / Published online: 16 November 2021

(c) The Author(s), under exclusive licence to Springer-Verlag GmbH Germany, part of Springer Nature 2021

\begin{abstract}
Objective The effectiveness of using food-grade coolant thickener solutions on the amount of aerosols generated and splatter contamination spread distance during simulated ultrasonic scaling was examined.

Materials and methods The study was performed using a phantom lower jaw placed on a black box. Simulated ultrasonic scaling was performed for 2 min using four coolant solutions: distilled water (control), $2 \%$ wt. polyacrylic acid (PAA), $0.4 \%$ wt. xanthan gum (XA), and 0.4\% wt. carboxymethyl cellulose (CMC). The simulation was repeated 10 times for each coolant group. The generated aerosols and droplets were quantified using a handheld particle counter, and the splatter contamination spread distance was evaluated by adding tracing fluorescent dye to the coolant reservoir supplying the scaler unit. One-way multivariate analysis of variance was performed to determine the difference among coolant groups $(a=.05)$.

Results The amount of aerosols and droplets and splatter contamination distance $(p<.001)$ pertaining to the three food-grade coolant thickener solutions were considerably lower than those for the distilled water (control). The PAA group exhibited a significantly lower splatter contamination distance $(p<.001)$ and a number of generated droplets $(p=.031)$ than those of the XA group. The CMC group exhibited a significantly lower splatter contamination distance $(p<.001)$ than that of the XA group. No statistically significant difference was observed between the PAA and CMC in terms of the three dependent variables $(p>.05)$. Conclusion The food-grade coolant thickeners could reduce the amount of generated aerosols and splatter contamination distance but not completely eliminate them. PAA and CMC solutions were more effective in reducing the aerosol/splatter during scaling compared to XA.

Clinical relevance Many dental procedures generate aerosols and splatter, which pose a potential risk to the patients and dental personnel, especially during the current COVID-19 pandemic.
\end{abstract}

Keywords Aerosols $\cdot$ Dental infection control $\cdot$ Food thickener $\cdot$ Mitigation strategies $\cdot$ SARS-CoV-2 $\cdot$ Splatter

Ra'fat I. Farah

Dr.rafat.farah@qudent.org; ri.farah@qu.edu.sa

Abdulrahman A. Althunayyan

Abdulrahman.Alth@gmail.com

Sanaa N. Al-Haj Ali

dr.sanaa.alhajali@qudent.org; s.alhajali@qu.edu.sa

Amani I. Farah

a.farah@zuj.edu.jo

1 Department of Prosthetic Dental Sciencs, College of Dentistry, Qassim University, Al-Mulaydah, Qassim, Kingdom of Saudi Arabia

2 College of Dentistry, Qassim University, Al-Mulaydah, Qassim, Kingdom of Saudi Arabia

3 Department of Orthodontic and Pediatric Dentistry, College of Dentistry, Qassim University, Al-Mulaydah, Qassim, Kingdom of Saudi Arabia

4 Department of Pharmacy, Faculty of Pharmacy, Al-Zaytoonah University of Jordan, Amman, Jordan

\section{Introduction}

Aerosols are produced during most dental procedures. These aerosols contain bodily fluids (saliva, mucus, and blood) of the patient, which may contain microorganisms from the oral cavity, upper respiratory tract, and blood. In addition, aerosolized cooling water may contain biofilms from the water-line of the dental unit. If the patient's microorganisms are highly pathogenic, the aerosolized microorganisms pose a potential risk to the dental team and other patients in the environment. Additionally, the smaller aerosol particles $(<10 \mu \mathrm{m}$ in diameter) that are generated during dental procedures have the greatest potential for transmitting infections by penetrating and reaching into the lower pulmonary region $[1,2]$.

Accordingly, in the context of the coronavirus pandemic, the Occupational Safety and Health Administration 
(OSHA) considered aerosol-producing dental procedures to pertain to the "highest risk" for potentially spreading SARS-CoV-2 and other respiratory viruses. Both the Centers for Disease Control and Prevention (CDC) and the American Dental Association (ADA) recommended that aerosol-producing dental procedures should be minimized and elective procedures should be postponed during the pandemic. Moreover, all dental procedures that involve aerosol production should be avoided for patients with active coronavirus. The oral cavity is a dynamic microbial environment that supports extremely complex polymicrobial biofilm communities [3]. As a result, dental procedures generate a significant amount of aerosolized microorganisms, which can reach concentrations of up to 100,000 microbes per cubic foot and travel up to 6 feet [4]. In such scenarios, dental personnel may be exposed to a high load of high-risk pathogens as they treat several patients per day, which, in turn, subjects them to a higher risk of more critical illnesses (as the severity of diseases is often linked to the amount of pathogen load) [1].

Several measures have been recommended to reduce the risk of aerosols being released during dental procedures, such as the use of a high-volume evacuator/suction, use of rubber dams, pre-procedural rinsing with antiseptic/ disinfectants agents such as peroxides and bovine iodine mouthwashes, personal hygiene, screening patients immediately prior to dental treatment, and use of PPE. However, no single method can minimize the risk of infection to dental personnel and other patients, and multiple precautionary strategies should be applied to gain maximum protection $[5,6]$.

Recently, certain researchers suggested the addition of a food-grade thickening agent to the cooling water used during dental procedures [7, 8]. These additives can alter the physical response of the water to different forces and therefore suppress the production of aerosols during dental procedures. This method is inexpensive and simple to implement and can eliminate the production of aerosols without the need for major modifications in equipment and procedures. Theoretically, this approach can eliminate the aerosols from the source before it comes into contact with dental personnel and other patients. Therefore, this approach is likely more effective than other protective measures, according to the CDC hierarchy of controls [9].

Currently, there are insufficient studies that assess the effect of the food-grade thickening agent on reducing dental aerosols and splatter; therefore, this study aimed to investigate the effect of a food-grade thickening agent on the reduction of the amount of produced aerosols and splatter contamination spread during a simulated dental scaling procedure. The tested null hypothesis was that the addition of a food-grade thickening agent to cooling water does not affect the amount of aerosols and droplets produced and spread of splatter contamination during a dental scaling procedure.

\section{Materials and methods}

This study was permitted/approved by the ethical committee at the College of Dentistry, and the simulation of the waterbased aerosol-producing scaling procedures was conducted in a closed room with the air ventilation system turned off. A lower training model jaw (AG-3 Frasaco GmbH, Tettnang, Germany) was placed in the center of the base of a black box $(45 \times 24 \times 100 \mathrm{~cm})$ that was open from one side. The handpiece of a portable ultrasonic scaler unit (UDS-K; Woodpecker, China) equipped with a conventional stainless steel scaler tip (P1T, Woodpecker, China) was fixed using a flexible mount holder such that the scaler tip engaged (tangentially in contact) the cervical third of the lower central incisor at an angle of $45^{\circ}$ upward. The coolant supply line from the reservoir to the ultrasonic scaler passed through a variable flow pump (Peristaltic dosing pump; Kamoer Fluid Tech Co., Ltd., Shanghai, China) to ensure adequate coolant supply, especially for a high viscosity coolant, and constant coolant supply at $40 \mathrm{~mL} / \mathrm{min}$ regardless of the coolant viscosity (Fig. 1).

To evaluate the effect of the food-grade thickening agent on the amount of produced aerosols and splatter contamination vertical spread, four groups of coolants were considered. Group 1 involved only deionized water as the control group. In the other groups, three coolant solutions were prepared by adding three food-grade thickener powders, specifically polyacrylic acid (PAA, CAS NO 9003-01-4), carboxymethyl cellulose (CMC, CAS NO: 9004-32-4), and xanthan gum (XA, CAS NO: 11138-66-2). These agents were chosen primarily because they are the thickening agents most frequently used in saliva substitutes [10]. In particular, groups $2-4$ included $2 \%$ wt. PAA, $0.4 \%$ wt. XA, and $0.4 \%$ wt. CMC. To prepare the coolant solutions, the food-grade thickening powders were slowly added to cold distilled water while applying high agitation to prevent agglomeration and lump formation owing to the rapid hydration of the thickener polymer.

Each simulated aerosol-producing scaling procedure was implemented for $2 \mathrm{~min}$ at full scaler power and a constant coolant flow rate of $40 \mathrm{~mL} / \mathrm{min}$. The amount of coolant flow rate was verified by running the scaler for $1 \mathrm{~min}$ and collecting the cooling solution in a graduated tube. The pump knob was used to adjust the pump speed until the desired flow rate was reached. The scaling simulation was performed 10 times for each coolant, with a total of 40 simulations performed for the four considered coolant solutions.

To compare the effect of the thickening agents, the amount of aerosol production and splatter vertical spread 
Fig. 1 Schematic representation of the study apparatus

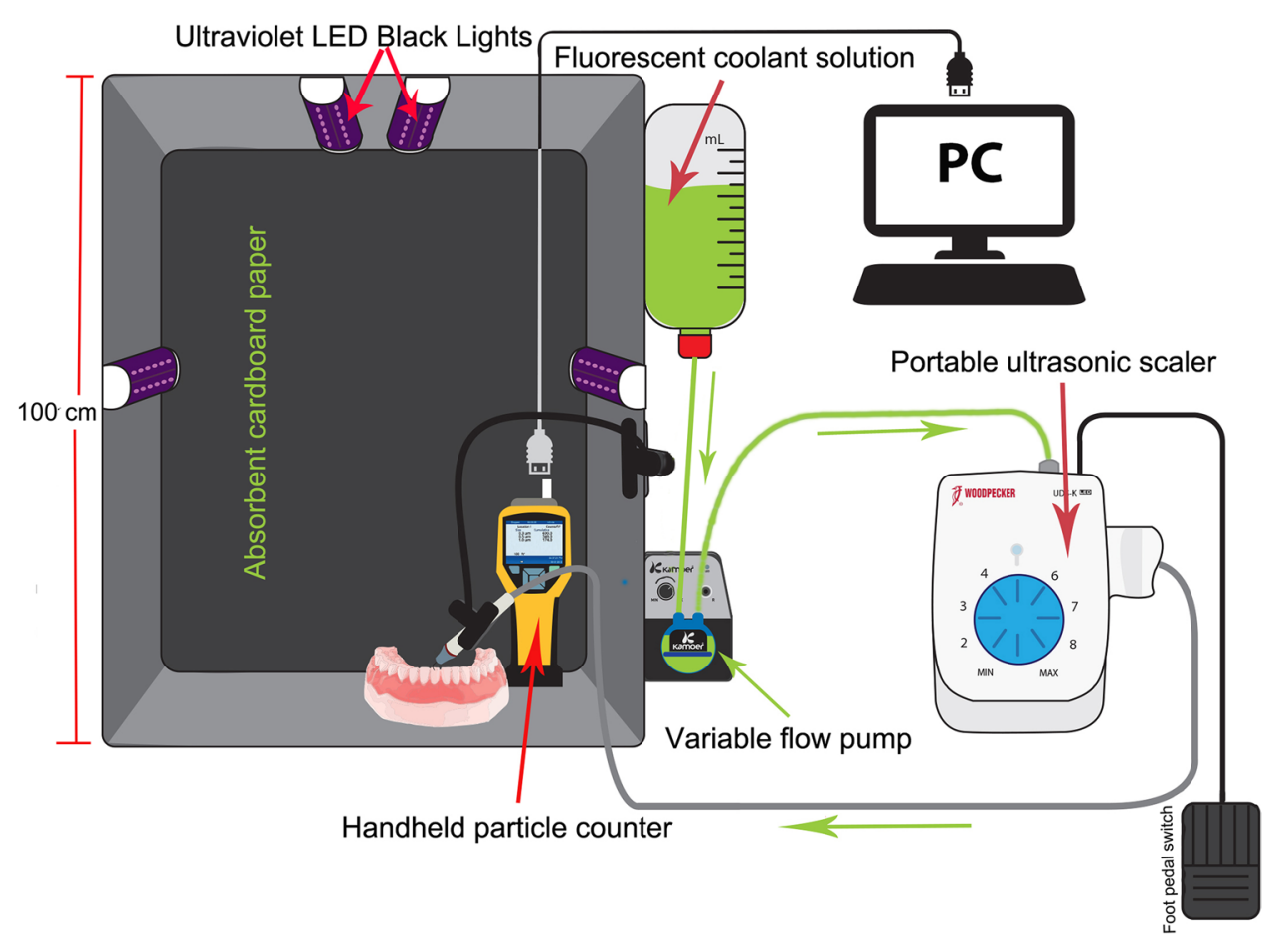

was quantified. To quantify the aerosols, a calibrated sixchannel handheld particle counter was used, which could detect the number of particles per liter in the air for particle sizes ranging from 0.3 to $10 \mu \mathrm{m}$ by using the laser scattering principle. The device was placed in the test black box at a distance of $10 \mathrm{~cm}$ from the scaler tip to test the air inlet of the device in all simulations. The device was operated in the continuous sampling mode. The particle count was exported from the device using a USB cable, and the numerical values (quantification) of the produced aerosols and droplets for each simulation were determined as the maximum particle count recorded during the simulation minus the baseline particle count for particle sizes of $0.5 \mu \mathrm{m}, 1.0 \mu \mathrm{m}$, and $2.5 \mu \mathrm{m}$ for aerosols and 0.5-10.0 $\mu \mathrm{m}$ for droplets [11-13].

To trace and visualize the splatter contamination vertical spread, a washable and water-soluble fluorescent dye (Tifoo Fluorescein Disodium Salt/i.e., Uranine, Marawe GmbH, Regensburg, Germany) was added to all coolant solutions at a concentration of $0.1 \mathrm{~g}$ per liter, and the test black box was equipped with ultraviolet LED black light (wavelength: 395-400 $\mathrm{nm}$ ). All the simulations were performed in a dark closed room. In each simulation, a new black thickcardboard sheet was used to line the back of the test box to visualize the absorbed florescent coolant and determine the splatter spread by measuring the maximum point reached by the fluorescent splatter in the vertical direction (Fig. 2). The numerical values of the splatter contamination spread were considered as the maximum distance (in centimeters) traveled by the splatter contamination in the vertical direction at the inner backside of the test box. The numerical values for

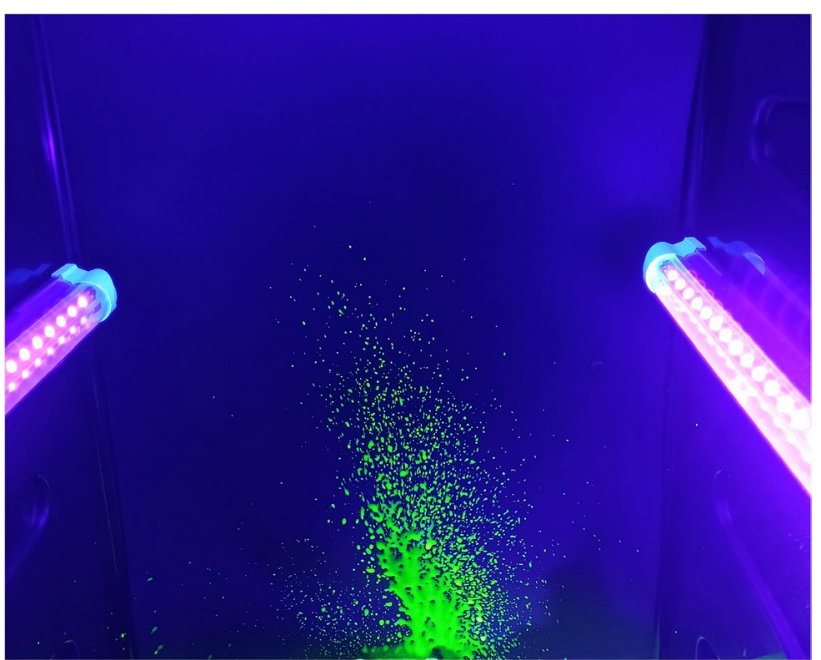

Fig. 2 The fluorescent splatter is shown on the absorbent cardboard sheet located in the back of the test box

each procedure for all coolant types were tabulated for the statistical analysis.

Data were analyzed using descriptive statistics and oneway multivariate analysis of variance (MANOVA) tests. Post hoc Tukey's test was performed to determine the statistically significant differences among groups. Preliminary assumption verification indicated that the data were normally distributed, as assessed using the Shapiro-Wilk test $(p>0.05)$; no univariate or multivariate outliers existed, as assessed by a box-plot and the Mahalanobis distance $(p>0.001)$, 
respectively; linear relationships existed, as assessed by a scatterplot; no multicollinearity $(r=0.888,0.978,0.885$, $p<0.001)$ occurred; and the variance-covariance matrices were homogenous, as assessed using Box's M test $(p<0.001)$. The statistical analysis was performed using a statistical software program (IBM SPSS Statistics, v20.0; IBM Corp) $(a=0.05)$.

\section{Results}

The MANOVA results indicated a statistically significant difference between the coolant solution groups in terms of the combined dependent variables, $F(9,82.898)=39.279$, $p<0.001$; Wilks' $\Lambda=0.018$; partial $\eta^{2}=0.740$. All three thickened coolant groups exhibited low aerosol and droplet particle counts (Fig. 3) and splatter contamination vertical distance (Fig. 4).

The follow-up univariate ANOVA tests indicated that the aerosol and droplet particle counts and splatter contamination distance were statistically significantly different among the coolant groups ( $p<0.001)$, according to the tests of between-subjects effects (Table 1).

The pairwise comparison Tukey post hoc tests highlighted that the three thickened coolant solutions exhibited statistically significantly lower mean aerosol and droplet particle counts and lower splatter contamination vertical distance compared to those of the water coolant $(p<0.001)$. The splatter contamination distance was not significantly different between the PAA and CMC groups $(p=0.130)$. However, both groups exhibited significantly lower splatter contamination than the XA group $(p<0.001)$. In terms of the aerosol particle counts, no statistically significant difference was observed among the three thickened coolant groups. However, the PAA group corresponded to a significantly lower generated droplet particle count compared with the XA group $(p=0.031)$. No significant differences were observed among other groups in terms of the generated droplet count (Table 2).

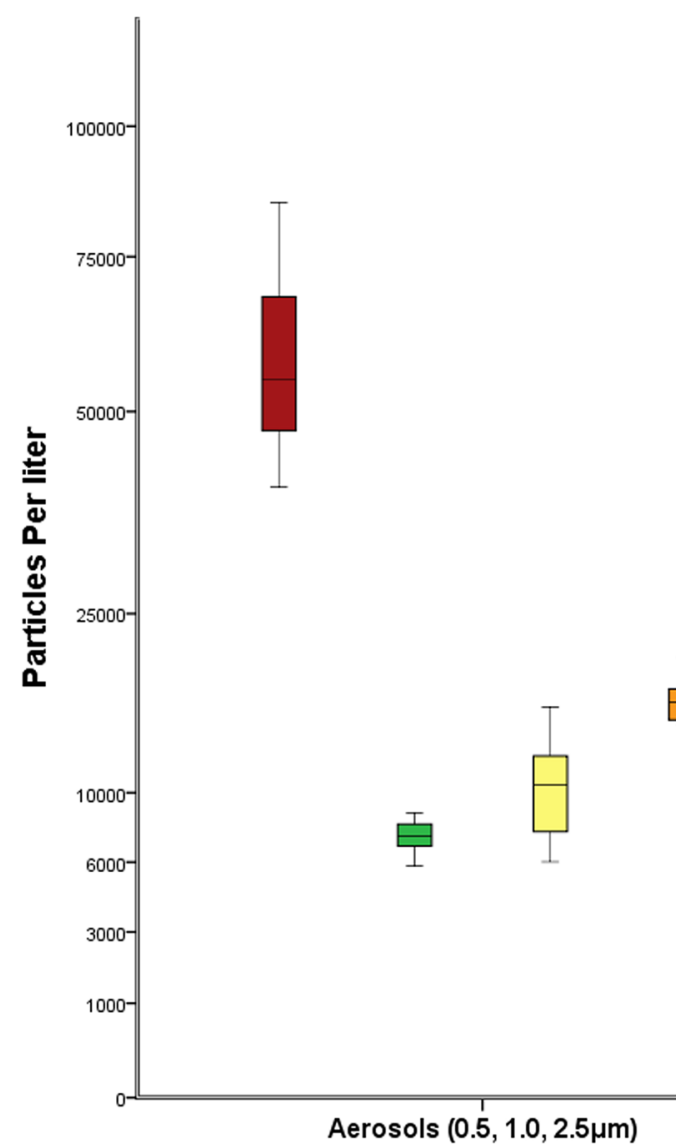

Coolant Solution

$\square$ Distilled Water/control $\square$ Polyacrylic acid $\square$ Carboxymethyl Cellulose $\square$ Xanthan Gum

Aerosols $(0.5,1.0,2.5 \mu \mathrm{m})$

Droplets $(>5-10 \mu \mathrm{m})$

\section{Particles Size}

Fig. 3 Box-plot illustrating the particle counts of aerosols and droplets generated in the four coolant solutions tested in the experiment 
Fig. 4 Box-plot depicting the vertical distance between splatter contaminations representing the four coolant solutions tested in the experiment

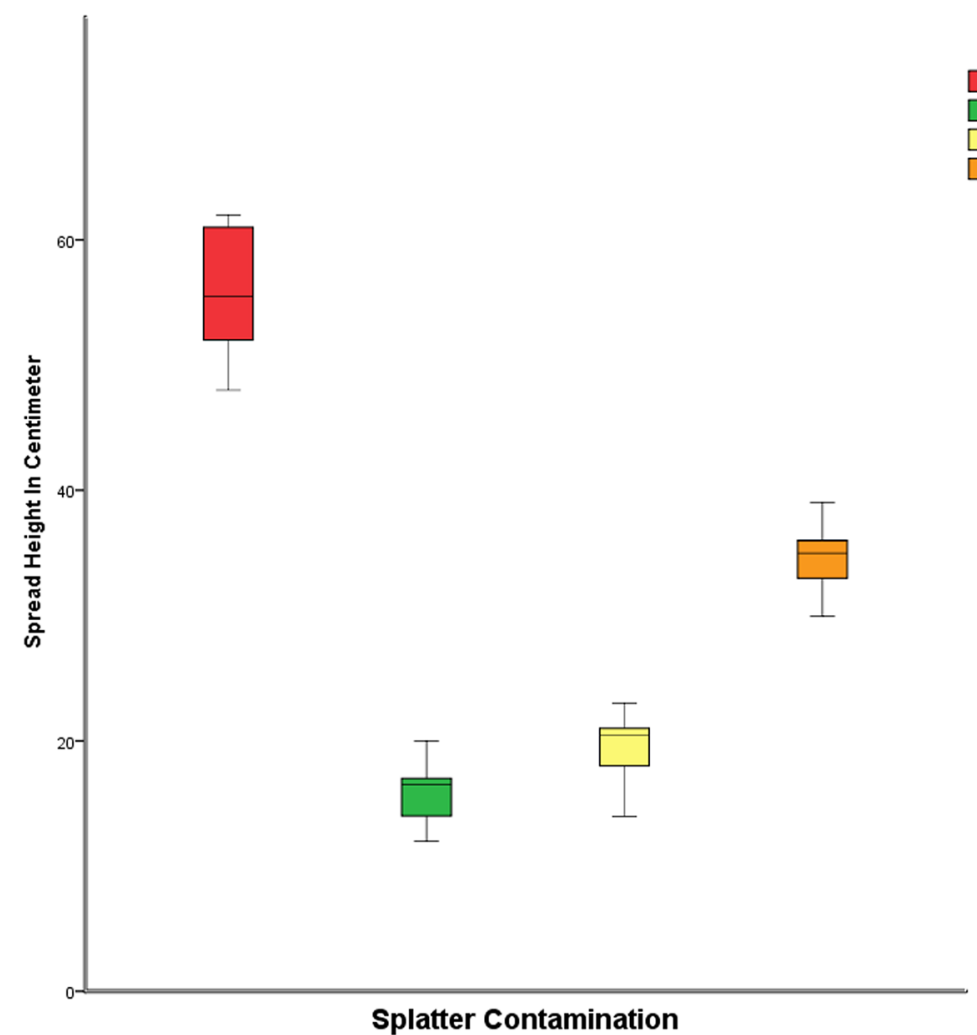

Coolant Solution

Distilled Waterlcontrol

Polyacrylic Acid

Carboxymethyl Cellulose

$\square$ Xanthan Gum

\section{Discussion}

In the current coronavirus pandemic, it has become necessary to address the issue of aerosol and splatter generation during certain dental procedures owing to their potential contribution as carriers of pathogens and the increased spread of pathogens within dental settings [14]. Therefore, in this study, the amount of generated aerosolized particles and splatter vertical spread during a simulated scaling procedure were investigated in a well-controlled environment. Furthermore, the effectiveness of the addition of three thickening agents to coolant solutions in mitigating aerosol production and splatter spread was examined. The aerosol particle concentrations were quantified using a handheld particle counter. This approach is considered a reliable method to investigate aerosol concentrations and their evolution in time and yields accurate results compared to the conventional aerosol measurement technique known as laser sheet scattering [15]. Moreover, handheld particle counters have been used in previous studies to quantify aerosols [16, 17]. A fluorescent dye was used to trace the extent of the vertical spread of the splatter. This method has also been used in many existing dental, ophthalmology, and medical studies to trace splatter [18-20].

The results showed that the generated aerosol and droplet count increased 10- to 13-fold compared to the baseline values when the scaling was performed using distilled water as a coolant without the addition of a thickening agent or the implementation of any mitigation procedure. This massive increase in the count of aerosolized particles, which may potentially be carriers of SARS-CoV-2 or other respiratory viruses, exhibits the degree of health hazard that a routine dental procedure may impose on patients and dental personnel. These values of the increased aerosolized particle concentration are comparable to those reported by Polednik [21], who indicated a nearly 16-fold increase in the count of particles having different sizes during various dental procedures. Furthermore, this study showed that the vertical extent of the projectile splatter was approximately $0.62 \mathrm{~m}$ above the site of operation (i.e., scaler tip) which is similar to the findings of a previous study [22]. This particular finding is of significance for open plan clinics such as dental hospitals and schools and may suggest that the barrier wall between clinics cubicles should be adequately high to prevent the spread of splatter that may be a carrier of different pathogens between adjacent dental units.

In this study, three food-grade thickening agents were used. These agents, which are "generally recognized as safe," are biodegradable, nontoxic, and biocompatible [23, 24]. They are used in food applications such as sauces and dressings, baked goods, beverages, desserts, and ice creams and in non-food applications such as oil field, personal care, pharmaceutical, and home care products [25]. In dental applications, these agents are often used in artificial saliva, 
Table 1 Univariate effects of coolant solution groups on splatter contamination vertical height and aerosol/droplet particle counts

\begin{tabular}{|c|c|c|c|c|c|c|c|}
\hline Source & Dependent variable & Type III sum of squares & df & Mean square & $F$ & $p$-value & $\begin{array}{l}\text { Partial } \\
\text { eta } \\
\text { squared }\end{array}$ \\
\hline \multirow[t]{3}{*}{ Corrected model } & Splatter spread height $(\mathrm{cm})$ & $9715.7^{\dagger}$ & 3 & 3238.6 & 283.394 & $<.001$ & .959 \\
\hline & Aerosols $(0.5 \mu \mathrm{m}, 1.0 \mu \mathrm{m}, 2.5 \mu \mathrm{m})$ & $18,150,225,726.6^{\ddagger}$ & 3 & $6,050,075,242.2$ & 87.577 & $<.001$ & .879 \\
\hline & Droplets $(>5-10 \mu \mathrm{m})$ & $26,544,516.6^{\S}$ & 3 & $8,848,172.2$ & 110.043 & $<.001$ & .902 \\
\hline \multirow[t]{3}{*}{ Intercept } & Splatter spread height (cm) & $39,312.9$ & 1 & $39,312.9$ & 3440.118 & $<.001$ & .990 \\
\hline & Aerosols $(0.5 \mu \mathrm{m}, 1.0 \mu \mathrm{m}, 2.5 \mu \mathrm{m})$ & $22,669,215,888.4$ & 1 & $22,669,215,888.4$ & 328.143 & $<.001$ & .901 \\
\hline & Droplets $(>5-10 \mu \mathrm{m})$ & $21,703,182.4$ & 1 & $21,703,182.4$ & 269.918 & $<.001$ & .882 \\
\hline \multirow[t]{3}{*}{ Coolant solution } & Splatter spread height (cm) & 9715.7 & 3 & 3238.6 & 283.394 & $<.001$ & .959 \\
\hline & Aerosols $(0.5 \mu \mathrm{m}, 1.0 \mu \mathrm{m}, 2.5 \mu \mathrm{m})$ & $18,150,225,726.6$ & 3 & $6,050,075,242.2$ & 87.577 & $<.001$ & .879 \\
\hline & Droplets $(>5-10 \mu \mathrm{m})$ & $26,544,516.6$ & 3 & $8,848,172.2$ & 110.043 & $<.001$ & .902 \\
\hline \multirow[t]{3}{*}{ Error } & Splatter spread height $(\mathrm{cm})$ & 411.4 & 36 & 11.4 & & & \\
\hline & Aerosols $(0.5 \mu \mathrm{m}, 1.0 \mu \mathrm{m}, 2.5 \mu \mathrm{m})$ & $2,486,999,319.0$ & 36 & $69,083,314.4$ & & & \\
\hline & Droplets $(>5-10 \mu \mathrm{m})$ & $2,894,639.0$ & 36 & $80,406.6$ & & & \\
\hline \multirow[t]{3}{*}{ Total } & Splatter spread height $(\mathrm{cm})$ & $49,440.0$ & 40 & & & & \\
\hline & Aerosols $(0.5 \mu \mathrm{m}, 1.0 \mu \mathrm{m}, 2.5 \mu \mathrm{m})$ & $43,306,440,934.0$ & 40 & & & & \\
\hline & Droplets $(>5-10 \mu \mathrm{m})$ & $51,142,338.0$ & 40 & & & & \\
\hline \multirow[t]{3}{*}{ Corrected total } & Splatter spread height (cm) & $10,127.1$ & 39 & & & & \\
\hline & Aerosols $(0.5 \mu \mathrm{m}, 1.0 \mu \mathrm{m}, 2.5 \mu \mathrm{m})$ & $20,637,225,045.6$ & 39 & & & & \\
\hline & Droplets $(>5-10 \mu \mathrm{m})$ & $29,439,155.600$ & 39 & & & & \\
\hline
\end{tabular}

$p$-value $<.05$ indicates significant difference

$d f$, degrees of freedom

${ }^{\dagger} R$-squared $=.959$ (adjusted $R$-squared $\left.=.956\right)$

${ }^{\ddagger} R$-squared $=.879$ (adjusted $R$-squared $=.869$ )

${ }^{\S} R$-squared $=.902($ adjusted $R$-squared $=.893)$

toothpaste, oral moisturizers, and local drugs delivery systems $[10,26]$. Food thickeners are also used for dysphagia patients to reduce the risk of aspiration [27]. These compounds, which have a high molecular weight, are water-soluble (soluble in cold water) and can exhibit an extremely high viscosity even at low concentrations. The materials hydrate in cold water to yield a viscous solution with pseudo-plastic flow behavior $[28,29]$.

The three thickened coolant solutions exhibited significantly reduced (but not completely eliminated) aerosol and droplet particle counts and splatter contamination spread. Therefore, the null hypothesis that the addition of food-grade thickening agents (in extremely low concentrations) would not affect the amount of produced aerosols and splatter vertical spread was rejected.

The aerosol suppression effects were not uniform for the three agents. The PAA and CMC groups were the most effective in reducing the particle counts and vertical splatter spread. The ability of XA in reducing the splatter vertical contamination spread was inferior compared to that of PAA and CMC. In addition, the ability of XA in suppressing the generation of droplets was highly inferior to that of the PAA group. A similar finding was reported by Plog et al.
[7], even though the authors used a different quantification methodology.

In general, the differences in the ability of the thickening agents to suppress aerosol production and splatter generation cannot be explained easily or predicted theoretically owing to the complicated physical and chemical interactions [30]. To this end, physicochemical analyses and rheological tests of the coolant fluid must be performed, which are beyond the scope of this study. Observation of the coolant rheological properties indicated that the thickening agent solutions exhibited pseudo-plastic (shear-thinning) behavior as the coolant viscosity decreased when passing through the water-line owing to the high shear rate in the test apparatus pump. However, when the solutions emerged from the scaler tip, the shear rate decreased. Therefore, the fluid viscosity increased, which prevented the atomization of water particles (because of viscoelastic forces), and the water particles coalesced around the scaler tip to form large water drops that eventually fell downward (Fig. 5) and pooled at the center of the box base owing to their high viscosity [31]. This phenomenon was in contrast to that of the water used as the control, which atomized/aerosolized owing to the kinetic vibration of the scaler tip and easily flowed over the 
Table 2 Tukey HSD multiple pairwise comparison of mean changes in splatter spread height, aerosols, and droplets among 4 coolant solutions

\begin{tabular}{|c|c|c|c|c|c|c|c|}
\hline \multirow[t]{2}{*}{ Dependent variable } & \multirow[t]{2}{*}{ Coolant solution $(I)$} & \multirow[t]{2}{*}{ Coolant solution $(J)$} & \multirow{2}{*}{$\begin{array}{l}\text { Mean difference } \\
(I-J)\end{array}$} & \multirow[t]{2}{*}{ Standard error } & \multirow[t]{2}{*}{$p$-value } & \multicolumn{2}{|c|}{$95 \%$ confidence interval } \\
\hline & & & & & & Lower bound & Upper bound \\
\hline \multirow{12}{*}{$\begin{array}{l}\text { Splatter spread } \\
\text { height }(\mathrm{cm})\end{array}$} & \multirow[t]{3}{*}{ Distilled water } & Polyacrylic acid & $39.50^{*}$ & 1.51 & $<.001$ & 35.43 & 43.57 \\
\hline & & $\begin{array}{l}\text { Carboxymethyl cel- } \\
\text { lulose }\end{array}$ & $36.10^{*}$ & 1.51 & $<.001$ & 32.03 & 40.17 \\
\hline & & Xanthan gum & $21.00^{*}$ & 1.51 & $<.001$ & 16.93 & 25.07 \\
\hline & \multirow[t]{3}{*}{ Polyacrylic acid } & Distilled water & $-39.50^{*}$ & 1.51 & $<.001$ & -43.57 & -35.43 \\
\hline & & $\begin{array}{l}\text { Carboxymethyl cel- } \\
\text { lulose }\end{array}$ & -3.40 & 1.51 & .130 & -7.47 & .67 \\
\hline & & Xanthan gum & $-18.50^{*}$ & 1.51 & $<.001$ & -22.57 & -14.43 \\
\hline & \multirow{3}{*}{$\begin{array}{l}\text { Carboxymethyl cel- } \\
\text { lulose }\end{array}$} & Distilled water & $-36.10^{*}$ & 1.51 & $<.001$ & -40.17 & -32.03 \\
\hline & & Polyacrylic acid & 3.40 & 1.51 & .130 & -.67 & 7.47 \\
\hline & & Xanthan gum & $-15.10^{*}$ & 1.51 & $<.001$ & -19.17 & -11.03 \\
\hline & \multirow[t]{3}{*}{ Xanthan gum } & Distilled water & $-21.00^{*}$ & 1.51 & $<.001$ & -25.07 & -16.93 \\
\hline & & Polyacrylic acid & $18.50^{*}$ & 1.51 & $<.001$ & 14.43 & 22.57 \\
\hline & & $\begin{array}{l}\text { Carboxymethyl cel- } \\
\text { lulose }\end{array}$ & $15.10^{*}$ & 1.51 & $<.001$ & 11.03 & 19.17 \\
\hline \multirow{12}{*}{$\begin{array}{r}\text { Aerosols }(0.5 \mu \mathrm{m}, \\
1.0 \mu \mathrm{m}, 2.5 \mu \mathrm{m})\end{array}$} & \multirow[t]{3}{*}{ Distilled water } & Polyacrylic acid & $52,843.80^{*}$ & 3717.08 & $<.001$ & $42,832.87$ & $62,854.73$ \\
\hline & & $\begin{array}{l}\text { Carboxymethyl cel- } \\
\text { lulose }\end{array}$ & $49,562.70^{*}$ & 3717.08 & $<.001$ & $39,551.77$ & $59,573.63$ \\
\hline & & Xanthan gum & $43,212.30^{*}$ & 3717.08 & $<.001$ & 33201.37 & $53,223.23$ \\
\hline & \multirow[t]{3}{*}{ Polyacrylic acid } & Distilled water & $-52,843.80^{*}$ & 3717.08 & $<.001$ & $-62,854.73$ & $-42,832.87$ \\
\hline & & $\begin{array}{l}\text { Carboxymethyl cel- } \\
\text { lulose }\end{array}$ & -3281.10 & 3717.08 & .814 & $-13,292.03$ & 6729.83 \\
\hline & & Xanthan gum & -9631.50 & 3717.08 & .063 & $-19,642.43$ & 379.43 \\
\hline & \multirow{3}{*}{$\begin{array}{l}\text { Carboxymethyl cel- } \\
\text { lulose }\end{array}$} & Distilled water & $-49,562.70^{*}$ & 3717.08 & $<.001$ & $-59,573.63$ & $-39,551.77$ \\
\hline & & Polyacrylic acid & 3281.10 & 3717.08 & .814 & -6729.83 & $13,292.03$ \\
\hline & & Xanthan gum & -6350.40 & 3717.08 & .334 & $-16,361.33$ & 3660.53 \\
\hline & \multirow[t]{3}{*}{ Xanthan gum } & Distilled water & $-43,212.30^{*}$ & 3717.08 & $<.001$ & $-53,223.23$ & $-33,201.37$ \\
\hline & & Polyacrylic acid & 9631.50 & 3717.08 & .063 & -379.43 & $19,642.43$ \\
\hline & & $\begin{array}{l}\text { Carboxymethyl cel- } \\
\text { lulose }\end{array}$ & 6350.40 & 3717.08 & .334 & -3660.53 & $16,361.33$ \\
\hline \multirow{12}{*}{$\begin{array}{l}\text { Droplets } \\
\qquad(>5-10 \mu \mathrm{m})\end{array}$} & \multirow[t]{3}{*}{ Distilled water } & Polyacrylic acid & $2046.60^{*}$ & 126.81 & $<.001$ & 1705.07 & 2388.13 \\
\hline & & $\begin{array}{l}\text { Carboxymethyl cel- } \\
\text { lulose }\end{array}$ & $1846.10^{*}$ & 126.81 & $<.001$ & 1504.57 & 2187.63 \\
\hline & & Xanthan gum & $1678.50^{*}$ & 126.81 & $<.001$ & 1336.97 & 2020.03 \\
\hline & \multirow[t]{3}{*}{ Polyacrylic acid } & Distilled water & $-2046.60^{*}$ & 126.81 & $<.001$ & -2388.13 & -1705.07 \\
\hline & & $\begin{array}{l}\text { Carboxymethyl cel- } \\
\text { lulose }\end{array}$ & -200.50 & 126.81 & .402 & -542.03 & 141.03 \\
\hline & & Xanthan gum & $-368.10^{*}$ & 126.81 & .031 & -709.63 & -26.57 \\
\hline & \multirow{3}{*}{$\begin{array}{l}\text { Carboxymethyl cel- } \\
\text { lulose }\end{array}$} & Distilled water & $-1846.10^{*}$ & 126.81 & $<.001$ & -2187.63 & -1504.57 \\
\hline & & Polyacrylic acid & 200.50 & 126.81 & .402 & -141.03 & 542.03 \\
\hline & & Xanthan gum & -167.60 & 126.81 & .556 & -509.13 & 173.93 \\
\hline & \multirow[t]{3}{*}{ Xanthan gum } & Distilled water & $-1678.50^{*}$ & 126.81 & $<.001$ & -2020.03 & -1336.97 \\
\hline & & Polyacrylic acid & $368.10^{*}$ & 126.81 & .031 & 26.57 & 709.63 \\
\hline & & $\begin{array}{l}\text { Carboxymethyl cel- } \\
\text { lulose }\end{array}$ & 167.60 & 126.81 & .556 & -173.93 & 509.13 \\
\hline
\end{tabular}

Based on observed means, the error term is mean square (error) $=80,406.639$

${ }^{*}$ The mean difference is significant at $p<.05$ level 


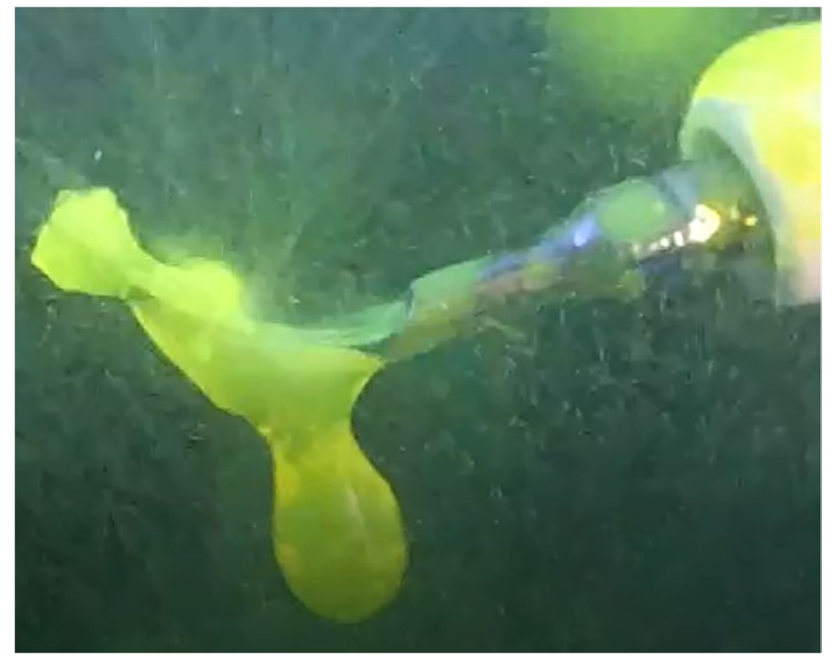

Fig. 5 Large fluorescent water drops coalesced around the scaler tip due to the high viscosity of the coolant fluid

box base. Although the pseudo-plastic behavior is not fully understood [32], the presence of negatively charged carboxyl groups $\left(\mathrm{COO}^{-}\right)$, which can form hydrogen bonds with more than one water molecule, may be responsible for the high viscosity of the tested thickening agent fluids and their rheological behavior [33].

Notably, the experiment was performed in a highly controlled environment, in a confined box placed in a closed room (to limit the effect of air flow on the particle counter device and aerosols and splatter dynamic behavior). Moreover, we attempted to standardize all the factors that can affect aerosolize generation and atomization of coolant solutions, such as the power setting of the scaler, coolant flow rate, spatial position, and grip resiliency of the handpiece [34]. This setting was selected because it can be easily reproduced. However, this study involves several limitations. First, this simulated in-vitro study may not reproduce the real-clinical scenarios in which the presence and pooling of saliva (which is a viscoelastic liquid) [35] can affect the amount and behavior of generated aerosols and splatter, and the room design and air ventilation system may affect the dynamic behavior of the aerosols and splatter [36]. Furthermore, owing to the limitations of the apparatus design, techniques, and measurement devices, the pattern and horizontal extent of splatter were not determined, and large aerosol particles with sizes ranging from 10 to $50 \mu \mathrm{m}$, which may contribute to the spread of different pathogens, were not quantified [37].

The findings of this study demonstrate the effectiveness of thickening agents in suppressing and reducing aerosol generation and the potential of their use as a supplement to other aerosol mitigation procedures. However, to ensure the practical use of these agents as additives in coolant fluids, certain aspects, such as the ability of the water-line system to handle viscous coolants (or any necessary modifications), effect of the thickening agents on the biofilms of the waterline system, biological effect of the food thickener solutions (oral microbial profiles, wound healing, etc.), and effect of these agents on various dental procedures such as bonding procedures must be further examined. Additionally, because the oral cavity harbors a complex microbiota whose composition may be influenced by a wide range of local and external factors $[38,39]$, it is crucial to examine the microbiological profile/status of prepackaged thickening coolant solutions that have been exposed to clinical environment contaminates over time, as well as their potential effect on the composition and equilibrium of the oral microbiota [40]. Therefore, clinical studies must be performed to examine the applicability and effectiveness of these agents on aerosol and splatter mitigation in real dental clinical settings. Such analyses can promote safer and aerosol- and splatter-free dentistry practices and facilitate the delivery of high-quality dental care while minimizing the risk to staff, patients, and the public.

\section{Conclusion}

Within the limitations of this in-vitro study, the following conclusions can be derived.

1. In the simulated scaling procedure using water coolant, the generated aerosol and droplet count significantly increased by up to 13-fold from the average baseline level, and the splatter contamination vertical spread reached up to $62 \mathrm{~cm}$.

2. The addition of thickening agents to the coolant solutions significantly reduced the aerosol and droplet counts by up to 8.2 -fold compared to the control water coolant group level. However, it did not completely eliminate these entities. Additionally, the vertical spread of the contaminated splatter was significantly reduced by up to $80 \%$ compared to the control group spread. However, the different agents suppressed the generation of aerosol/ splatter to varying degrees.

3. PAA and CMC were more effective in suppressing aero$\mathrm{sol} /$ splatter generation during the simulated scaling procedure compared with XA.

\section{Declarations}

Ethics approval This article does not contain any studies with human participants or animals performed by any of the authors. This study was conducted in full accordance with the World Medical Association 
Declaration of Helsinki, and ethical approval was obtained as per the university's protocols by the ethics committee at the College of Dentistry of Qassim University (EA/M-2021-4001).

Consent to participate For this type of study, formal consent is not required.

Conflict of interest Ra'fat Farah declares that he has no conflict of interest. Abdulrahman Althunayyan declares that he has no conflict of interest. Amani Farah declares that she has no conflict of interest. Sanaa Al-Haj Ali declares that she has no conflict of interest.

\section{References}

1. Harrel SK, Molinari J (2004) Aerosols and splatter in dentistry: a brief review of the literature and infection control implications. J Am Dent Assoc 135(4):429-437

2. Gund M, Isack J, Hannig M, Thieme-Ruffing S, Gärtner B, Boros G, Rupf S (2021) Contamination of surgical mask during aerosolproducing dental treatments. Clin Oral Investig 25(5):1-8

3. Sedghi L, DiMassa V, Harrington A, Lynch SV (2000) Kapila YL (2021) The oral microbiome: role of key organisms and complex networks in oral health and disease. Periodontol 87(1):107-131

4. Miller RL (1976) Generation of airborne infection by high speed dental equipment. J Am Soc Prev Dent 6(3):14-17

5. Klyn SL, Cummings DE, Richardson BW, Davis RD (2001) Reduction of bacteria-containing spray produced during ultrasonic scaling. Gen Dent 49(6):648-652

6. Centers for Disease Control and Prevention (CDC). https:// www.cdc.gov/coronavirus/2019-ncov/hcp/dental-settings.html. Accessed 27 Dec 2020

7. Plog J, Wu J, Dias YJ, Mashayek F, Cooper LF (1994) Yarin AL (2020) Reopening dentistry after COVID-19: complete suppression of aerosolization in dental procedures by viscoelastic Medusa Gorgo. Phys Fluids 32(8):083111

8. Yarin AL, Cooper LF, Plog J, Wu J, Dias YJ, Mashayek F (2020) "Irrigation solution to reduce/eliminate aerosol generation during dental and surgical procedures," Provisional Patent Application UIC 2020-172-01

9. Centers for Disease Control and Prevention(CDC). https://www. cdc.gov/niosh/topics/hierarchy/default.html. Accessed 27 Dec 2020

10. Amerongen AN, Veerman E (2003) Current therapies for xerostomia and salivary gland hypofunction associated with cancer therapies. Support care Cancer 11(4):226-231

11. World Health Organization. Modes of transmission of virus causing COVID-19: implications for IPC precaution recommendations. https://www.who.int/news-room/commentaries/detail/ modes-of-transmission-of-virus-causing-covid-19-implicationsfor-ipc-precaution-recommendation. Accessed 27 Dec 2020

12. Chanpong B, Tang M, Rosenczweig A, Lok P, Tang R (2020) Aerosol-generating procedures and simulated cough in dental anesthesia. Anesth Prog 67(3):127-134

13. Morawska L, Johnson GR, Ristovski ZD et al (2009) Size distribution and sites of origin of droplets expelled from the human respiratory tract during expiratory activities. J Aerosol Sci 40(3):256-269

14. Sommerstein R, Fux CA, Vuichard-Gysin D, Abbas M, Marschall J, Balmelli C, Troillet N, Harbarth S, Schlegel M, Widmer A, Swissnoso, (2020) Risk of SARS-CoV-2 transmission by aerosols, the rational use of masks, and protection of healthcare workers from COVID-19. Antimicrob Resist Infect Control 9(1):100
15. Somsen GA, van Rijn CJM, Kooij S, Bem RA (1994) Bonn D (2020) Measurement of small droplet aerosol concentrations in public spaces using handheld particle counters. Phys Fluids 32(12): 121707

16. Yang M, Chaghtai A, Melendez M, Hasson H, Whitaker E, Badi M, Sperrazza L, Godel J, Yesilsoy C, Tellez M, Orrego S, Montoya C, Ismail A (2021) Mitigating saliva aerosol contamination in a dental school clinic. BMC Oral Health 21(1):52

17. Nulty A, Lefkaditis C, Zachrisson P, Van Tonder Q, Yar R (2020) A clinical study measuring dental aerosols with and without a high-volume extraction device. Br Dent J. https:// doi.org/10.1038/s41415-020-2274-3

18. Bentley CD, Burkhart NW, Crawford JJ (1994) Evaluating spatter and aerosol contamination during dental procedures. J Am Dent Assoc 125(5):579-584

19. Felfeli T, Rai AS, Braga-Mele R, Mandelcorn ED, Hatch W, Rai AS (2021) Spread of respiratory droplets in a simulated ophthalmic surgery. Ophthalmology 128(6):945-947

20. Canelli R, Connor CW, Gonzalez M, Nozari A, Ortega R (2020) Barrier enclosure during endotracheal intubation. N Engl J Med 382(20):1957-1958

21. Polednik B (2014) Aerosol and bioaerosol particles in a dental office. Environ Res 134:405-409. https://doi.org/10.1016/j. envres.2014.06.027

22. Revathi B, Muralidharan N (2019) Evaluation of extent of aerosols around dental chair during dental treatments. Drug Invent Today 12(10):146-148

23. Cash JM, Caputo SJ (2010) Cellulose Derivatives. In: Imeson A (ed) Food stabilisers, thickeners and gelling agents, 1st edn. Blackwell Publishing Ltd, Oxford, pp 95-113

24. Xanthan SG, Gum, (2010) In: Imeson A(ed) Food stabilisers, thickeners and gelling agents, 1st edn. Blackwell Publishing Ltd, Oxford, pp 325-343

25. Brady J, Durig T, Lee PI, Li JX (2017) Polymer properties and characterization. In: Qiu Y, Chen Y, Zhang GG, Yu L, Mantri RV (eds) Developing solid oral dosage forms pharmaceutical theory \& practice, 2nd edn. Academic Press, London, pp 181-221

26. Tarawneh O, Hamadneh I, Huwaitat R, Al-Assi AR, El Madani A (2021) Characterization of chlorhexidine-impregnated cellulose-based hydrogel films intended for the treatment of periodontitis. Biomed Res Int 15:9853977. https://doi.org/10.1155/ 2021/9853977

27. Cichero JA (2013) Thickening agents used for dysphagia management: effect on bioavailability of water, medication and feelings of satiety. Nutr J 12:54. https://doi.org/10.1186/ 1475-2891-12-54

28. Benchabane A, Bekkour K (2008) Rheological properties of carboxymethyl cellulose (CMC) solutions. Colloid Polym Sci 286:1173. https://doi.org/10.1007/s00396-008-1882-2

29. Ozgur A, Dogan M, Karaman S (2017) Rheological interactions of the xanthan gum and carboxymethyl cellulose as alternative to pectin in organic acid-sucrose model system: simplex lattice mixture design approach. Eur Food Res Technol 243:1041-1056. https://doi.org/10.1007/ s00217-016-2809-7

30. Mann KA, Deutsch S, Tarbell JM, Geselowitz DB, Rosenberg G, Pierce WS (1987) An experimental study of Newtonian and nonNewtonian flow dynamics in a ventricular assist device. J Biomech Eng 109(2):139-147

31. Furuse H, Toda K (1999) Analysis of flow behavior of non-Newtonian fluids based on a concept of traveling force. J Biosci Bioeng 87(2):218-223

32. Aytouna M, Paredes J, Shahidzadeh-Bonn N, Moulinet S, Wagner C, Amarouchene Y, Eggers J, Bonn D (2013) Drop formation in non-Newtonian fluids. Phys Rev Lett 110(3):034501 
33. PettersSS PD, Claflin MS, Levin EJT, PettersMD ZPJ, Kreidenweis SM (2017) Hygroscopicity of organic compounds as a function of carbon chain length and carboxyl, hydroperoxy, and carbonyl functional groups. J Phys Chem A 121(27):5164-5174

34. Koletsi D, Belibasakis GN, Eliades T (2020) Interventions to reduce aerosolized microbes in dental practice: a systematic review with network meta-analysis of randomized controlled trials. J Dent Res 99(11):1228-1238

35. Kim B, Lee SS, Yoo TH, Kim JM (2020) Viscoelastic particle focusing in human biofluids. Electrophoresis. https://doi.org/10. 1002/elps.202000280J

36. Jarvis MC (2020) Aerosol transmission of SARS-CoV-2: physical principles and implications. Front Public Health 8:590041. https:// doi.org/10.3389/fpubh.2020.590041
37. Jayaweera M, Perera H, Gunawardana B, Manatunge J (2020) Transmission of COVID-19 virus by droplets and aerosols: a critical review on the unresolved dichotomy. Environ Res 188:109819. https://doi.org/10.1016/j.envres.2020.109819

38. Kaan AM, Kahharova D (2000) Zaura E (2021) Acquisition and establishment of the oral microbiota. Periodontol 86(1):123-141

39. Wade WG (2000) (2021) Resilience of the oral microbiome. Periodontol 86(1):113-122

40. Boaden E, Thomas L, Higham S, Watkins C (2020) Microbiological analysis of water and thickeners used for people with dysphagia. Br J Community Nurs 25(Sup8):S16-S24

Publisher's note Springer Nature remains neutral with regard to jurisdictional claims in published maps and institutional affiliations. 